\title{
A specter of logical challenges haunts smart grid
}

\author{
N. Khan ${ }^{*}$, S. Rauf, N. Abas, A. Kalair \\ Department of Electrical Engineering, COMSATS Institute of Information Technology, Park Road, Islamabad, Pakistan
}

\begin{abstract}
Smart and super grid visions have attracted electrical engineers worldwide. Smart grid offers innumerable advantages over conservative electric grid due to widespread integration of information and communication technologies (ICT). Information technology (IT) stimulates conscious in dumb electric grid hardware to think at its own how to operate economically in varying load conditions conducting real-time state estimation. Smart grid promises to offer bidirectional power flow capability and self-healing ability against faults. Advance metering infrastructures (AMI) help utilities track down power thefts supplying consumer home automation facilities. Smart grid helps stiff utilities to reduce operational losses and generation deficient utilities to implement live load shedding instead of revolving blackouts to help customers keeping their lights on during virtual load shedding. Smart grid promises package is subject to its complete implementation by the end of long road ahead. Communication capacity and speed limitations, cyber security risks, faults and traffic congestions have to be considered prior to rollout. This paper describes a live load shedding scheme for existing electric grids on $11 \mathrm{kV}$ feeders using smart grid option and evaluates technical, economic, societal and bio-effects challenges that smart grid vision might face ahead.
\end{abstract}

Keywords: Smart grid, bi-directional, self healing, live load shedding, energy crisis

\section{Introduction}

Electricity is the cleanest form of energy ever known to mankind. Modern life and industry thrives on incessant supply of power. Electric grid has been supplying power to consumers for 131 years but is now running down to meet power quality and quantity demands. Power professionals believe the integration of information and communication technologies (ICT) in electric grid might support the derelict power system through minimizing line losses, reducing power pilferages, clamping peak power demands, increasing generation efficiency, economic power system operation, real time state estimation and accurate load forecasting. In term SmartGrid the word "smart" refers to intelligence or thinking capability and "grid" to electric hardware infrastructure between power plants and consumers. Electric grid consists of substations, transmission and distribution lines. Introduction of term SmartGrid in electrical engineering is like a new machine in remote village. SmartGrid is a novel vision but not strange to $21 \mathrm{st}$ century power professionals. Conventional electric grids have long been using telemetry, power line communications, remote terminal unit (RTU), digital energy meter, microwaves and supervisory control $\&$ data acquisition (SCADA) systems.

Amin and Wollenberg coined the term smart grid in 2005 in their article "Toward a Smart Grid". Electric grid is a collective term for all transmission lines, circuit breakers, substations, bus bars, transformers and ancillary infrastructures which transport electricity from power houses to domestic, commercial and industrial consumers. Conventional grid is unidirectional as power flows from plants to consumers. A smart grid is a modern version of the conventional grid using bulk information and seamless communication technologies to gather data to inform or act on it in an automated fashion to improve the overall efficiency and reliability. Utilities often can not supply electricity, especially during peak hours, to keep up with consumer demands, leading to unreliable power quality, brownouts, low voltages, blackouts and revolving load shedding.

\footnotetext{
* Manuscript received March 22, 2013; revised May 24, 2013.

Corresponding author. Tel.:+92-51-0300-6490048; E-mail address: nasrullahk@yahoo.com.
} 
Smart grid rollout needs huge investment to be recovered over times to come. Consumers look at smart grid in terms of money, safety and security in the light of their earlier experiences with computerized systems. IT and ICT manufacturers, middle men and vend0rs with invested business interests use knotty jargon to prove the worth of investments on smart grid. Change is always a strenuous phase and transformation of present widespread electric grid to new smart or super grid is a grand power and energy transition. It is a defining moment in 131 years long history, starting from Edison's DC power stations to modern combined-cycle AC power plants. Smart meter manufacturers and IT experts believe the smart grid enables utilities to detect power thefts, meter reversing, payment irregularities, direct mains connections, total harmonic distortions, load, and peak load violations. Smart grid in-build features will enable generators to respond dynamically in time to rising power demands and relays in the case of faults. Protection, instrumentation and control engineers recognize the importance of communication technologies but utility managers generally look at revenue collection aspects of smart grid package.

There is general consensus among power and energy engineers the growth of energy demand has surpassed the energy generation rate can grow by traditional means. Negawatts notion requires safe integration of utility scale renewable energy sources feeding into transmission system and distributed energy resources (DER) feeding into distribution system. A decentralized power storage system for the time varying nature of wind and photovoltaic sources may cause unbalanced loading on parts of the grid, allowing active participation of consumers through demand side management (DSM) are claimed to be sustainable solutions to power crisis [1]. Electrical islanding schemes requires equating generation and demand need integration of more advanced protection and control technologies that ensure grid stability [2]. Hence, the concept of smart grid has emerged, encompassing the cyber-physical infrastructure including wide-area monitoring, bi-directional power flow and communication facilities. Communication is basis of smart grid superstructure therefore design for physical, data and network communications layers have become topic of intense debate. Researchers are evaluating PLC, BPL, cable, fibre, WiMAX, WiFi, DSL and cellular networks and routing protocols for communicating among various organs of smart grid [3].

Bulk scale power thefts are not possible without complicity of utility employs. Utility colluding employees and private beneficiary consumers look at smart grid as potent danger to their vested interests. Primary drivers of smart grid vision are high power demands, climate changes, renewable energy resources and operation losses. Smart grid promoters believe the integration of ICT in electric grid will increase productivity and reduce losses. Consumers have been hearing load anvil chorus of sustainability and flexibility and resiliency, and supervision and marketing for quite a few years yet electric grid could evolve into a real smart grid [4]. Motivation for smart grid comes from IT experts and communication engineers who are not well aware of conventional electric grid which they are supposed to upgrade to smart grid status. Power engineering students often ask about the ultimate configuration of smart grid vision as different authors paint different pictures depending upon their professional background. I asked a small group of electrical engineering students to sketch the picture of something unseen such as a giant. None of two pictures tallied with one another but one thing was common $35 \%$ percent students emphasized on forked teeth, $30 \%$ on awful eyes, $20 \%$ on jagged nails and $15 \%$ on spiky hairs. I guess they have understood the reason after seeing each other's sketches as none of them had seen the real giant like us all.

Smart grid snowballs booming power companies offering support to sustain dilapidating weak utilities. Smart grid offers high quality power supplies to rich utilities and provides online live load shedding facility to generation deficient utilities. Generation deficient utilities may replace revolving load shedding by live load reduction schemes to facilitate their consumers. This facility helps weak utility customers to have at least light and fans facilities instead of complete blackout during sultry summers. Hundreds of utilities worldwide execute load shedding throughout the year due to hydel and oil based generation facilities. Strong utilities can supply reliable power quality to their customers shaving peak demands and weak utilities may control line losses maintaining continuity of minimal power supply by live load shedding scheme illustrated in Fig. 1. 


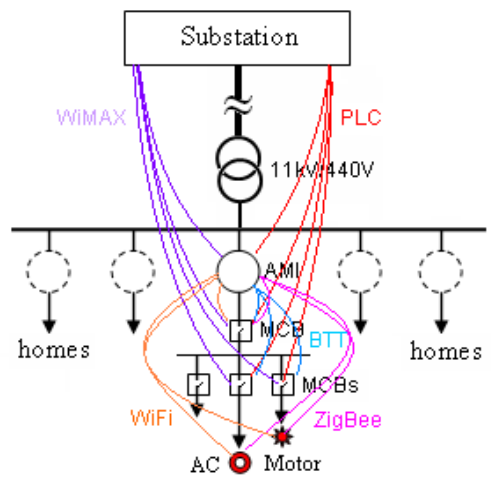

Fig.1. Live load shedding scheme using ICT devices.

Power line communication (PLC) has been used since 1900s. PLC has long been used for remote metering [5] and load control [6]. Electric grid utilities have been using capacitor coupling current transformers (CVT) for injecting PLC signals on high voltage lines and special couplers [7] to bypass MV/LV transformers for home automation but researchers have shown the PLC signals can penetrate through MV/LV transformers [8]. USA and Victoria are using Wimax radio systems for quick rollout of smart grid. Europe is choosing PLC systems as ERDF in France trialing a 300,000 meter PLC system pilot project using G3-PLC modems. G3-PLC modems use 35.9 to $90.6 \mathrm{kHz}$. PLC in home area networks was considered noisy earlier but recent developments allow it to work comparable to wired local area networks. A smart home is integral part of smart grid. Comparison of PLC to other competing technologies in market is shown in Table 1.

Table 1. Comparison of small range communication technologies [9]

\begin{tabular}{ccccc}
\hline \hline Technology & Media & Data Rate $(\mathrm{Mb} / \mathrm{s})$ & QoS & Cost (\$) \\
\hline 10BaseT & UTP & 10 & No & 10 \\
100BaseT & UTP & 100 & No & 10 \\
Bluetooth & Wireless & 1 & Yes & $5 /$ chip \\
HomeRF 2.0 & Wireless & 10 & Yes & 70 \\
IEEE 802.11b & Wireless & 11 & No & 80 \\
HomePNA 2.0 & Phone line & 10 & No & 60 \\
HomePlug & Powerline & 14 & Yes & 70 \\
\hline \hline
\end{tabular}

Data rates between refrigerators, microwave, AC and TV are limited to bytes, TV and VCR Kbytes and PC to PC or VCR to PC in Mbytes. Inverter-based loads such as AC, PC, fluorescent lights and energy savers decrease the self regulation characteristics of residential and industrial loads. Under frequency load-reduction control scheme (ULCS) can reduce the consumption of loads by $5 \%$ when the system frequency falls below $49.2 \mathrm{~Hz}$. It allows starting again after 10 minutes [10]. Controlling power through power line communication or wireless technologies is a long tested experience not a new trial. Smart grid philosophy can be implemented on existing ICT technologies. Several researchers have already introduced multiple blanket load shedding schemes. Live load shedding on $11 \mathrm{kV}$ feeders using master-slaves scheme can help reducing auxiliary loads during peak hours instead of buying expensive powers. Implementation of smart grid would allow additional solar and wind powers from prosumers during peak hours. A utility needs is to deploy smart miniature circuit breakers (MCB) next to meter on point of common coupling (PCC) expecting the customers to cooperate, although options available to deal with non-cooperative customers through mains $\mathrm{MCB}$. In the context of home automation the advance metering infrastructure (AMI) can control loads using blue tooth technology. Daily, weekly and monthly load reduction schemes may be fed to AMI through wireless ZigBee (advance version XBee Pro 900), power line communications (PLC) and internet based control schemes [11]. PLC may be attractive for utilities for their long earlier experiences. 
Although the available communication is fast enough, the computational needs for real-time control are still not well understood [12]. Even peak shaving also can compromise system stability. Small scale simulations and field trials are really no guarantee of all right. PLC being part of system is likely to be better option compared to other communication options which have their own timing issues to be discussed later under technical challenges. Smart Grid might use multiple types of communications technologies such as fibre optics, wireless and wire line. PLC can be used for automatic meter reading (AMR) and advanced metering infrastructure (AMI) which constitute the first step towards smart grid rollout. PLC based smart grid may face pressure due to lack of standard [13] and commercial reasons. Broadband PLC was developed to access internet in HAN not for protection and control scale applications. However a coexistence success story of PHY/MAC scheme (CENELEC EN 50065) has allowed NB-PLC solutions to flourish in the market for two decades.

Smart grid is a system of systems with unrelenting business and research possibilities. Electrical engineers work together with computer and communication experts to implement ICT for SmartGrid options; and energy engineers to envision SuperGrid to transport power and fuel energies. Liquid hydrogen acts as cryogenic coolant for superconducting wires transporting hydrogen through holes and electricity through their metallic surfaces [14]. European countries can convert abundant sunshine in Arab and African deserts into electricity and hydrogen using photovoltaic (PV) and solar thermal technologies. China and Europe can import oil and gas by converting it into liquid hydrogen and clean electricity phases leaving behind side products on site. Super grid vision is shown in Fig.2

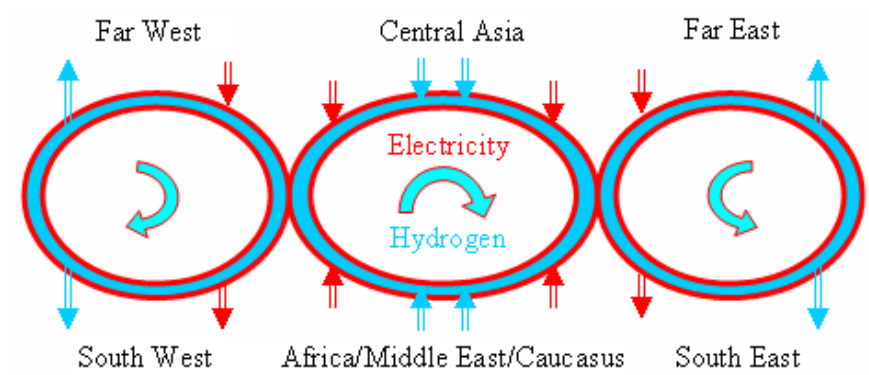

Fig. 2. Vision of regional/global cooperative super smart grid.

A new version of smart grid may take the form of regional cooperative corporate utilities. Old examples include interconnections between USA-Canada, Thailand-Malaysia and Europe. Pike Research reported a recent example of 13 African countries (SAPP) having 60,000 MW power capacity for their 189 million people, which is more than Pakistan and India. If Pakistan and India agree to a common power corporate at SARC level then it can solve their load shedding problems. Pakistan has opportunity to set up regional cooperative utilities with help of Iran, Afghanistan, Central Asian States and Turkey. The Caucasus region is home of oil, natural gas and electricity. World Bank advised Pakistan long ago to buy cheap power from Central Asian States. Pakistan tried to get power from Tajikistan and gas from Uzbekistan but war in Afghanistan did not let it be materialized. Different parts of the world can set up local regional cooperative power, oil and gas companies allowing space for transnational super grid for energy transmissions. World community is undergoing the third industrial revolution in which power and energy systems are being shifted from fossil fuels to alternative fuels and renewable energy resources. Smart grid can play symbolic role if it is transformed in collaboration with power engineers.

\section{Technical Challenges}

Smart grid vision stands on abundant communication and computational abilities yet to be integrated into existing electric grid over decades to come. Utilities welcome the smart and super grid notions, but power and control engineers look at the spatial, temporal and bandwidth limitations of communication technologies. Electric grid is one of the most complex systems, which becomes even more complex, when 
we dig deeper. Power engineers are worried on the integration of intelligence in dumb grid, which will create arguing ability in hardware during fault that might cause further delays in execution of trip messages. To check the speed of two commercial mobile companies, we sent "Hi" message to ourselves pressing start in parallel with send buttons. One network took 4 to 5 seconds whilst other elapsed 6 to 7 seconds. It is rare but some times it takes quite longer when there is defect or congestion in communication network. Protection and control signals can afford only 3 to $10 \mathrm{~ms}$ delays to execute trip and control messages. Power systems are designed so as to withstand fault for 3 seconds on high voltage transmission lines or heavily loaded bus bars. Public concerns are security, safety and electricity continuity or may be the cost of AMI meter but power engineers concerns are valid that can not be conceded. Present electric grid is like a sleeping giant who if rises may deny master's decisions. Before opening the Pandora box (rollout) we must rethink on how far the zombie can go. Several computer and communication experts [15] have pointed out timing, bandwidth and security limitations of information and communication technologies to cope with speed, security and real-time operational requirements of next generation smart grids. Smart grid initiatives aim at transforming electric grid into a flexible and intelligent power utility for real-time monitoring energy consumption and system behaviour, controlling loads, when necessary through IEDs connected across home area network (HAN).

Smart meters collect consumption data to concentrator nodes which take it to utility data centres for processing [16]. A smart grid may consist of seven logical domains consisting of generation, transmission, distribution, consumers, markets, services providers [16-17]. Smart grids incorporate Home (HAN) and Wide Area Networks (WAN). A HAN connects the consumer smart devices in home with the utility smart meter. The HAN can communicate using Zigbee, wired or wireless Ethernet, or Bluetooth technologies. A WAN being a wider network can connect the smart meters to service providers and utility centres. A WAN can use WiMAX, 3G/GSM/LTE, PLC and fibre optics (OPGW) for communication. Smart meter is basically a gateway between the consumer devices and the external parties to provide the desired information as shown in Fig.3 [17].

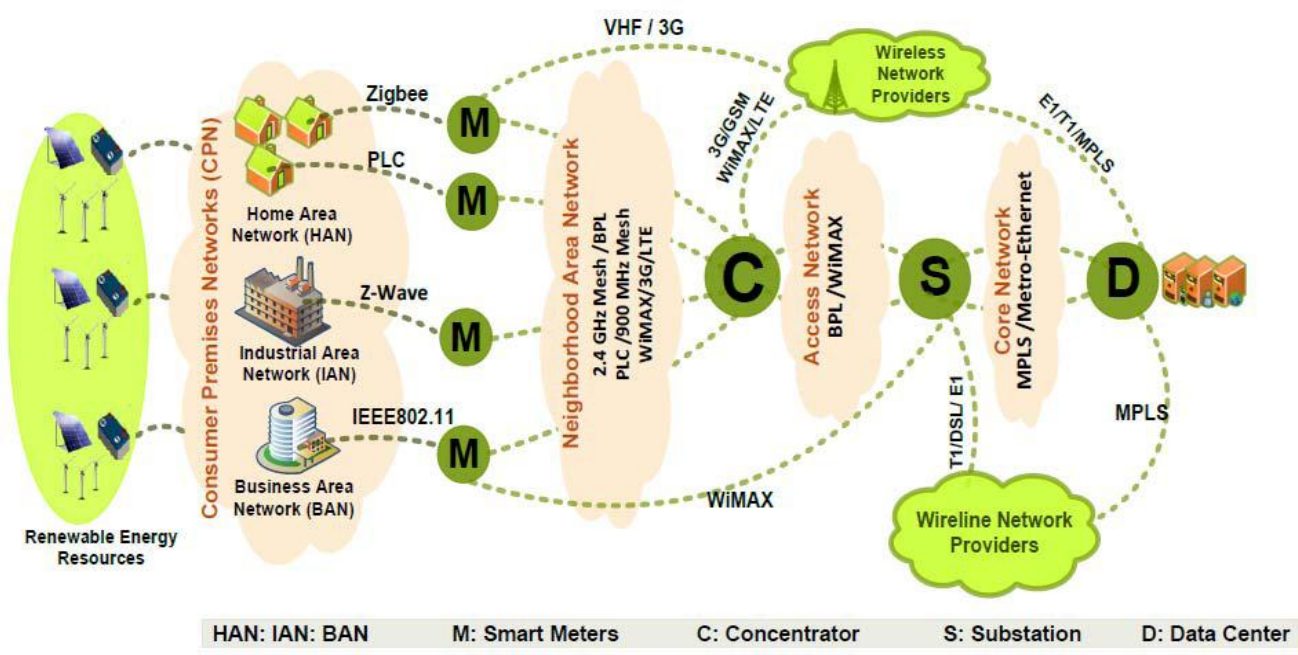

Fig.3. Smart grid network architecture [After 17, 18].

Smart grid network vulnerabilities consist of unauthorized access to HAN, BAN, AMI, data concentrator, substations, and data centres. Software malware may limit performance of smart grid and compromise communication equipment through false information injection, eavesdropping, and other unknown techniques. South Korea has finished the first phase of his smart grid project and today (20 March 2013) all of Korean banks, utilities and government sites have fallen victim to cyber attack. Electronic intrusions have already caused billions dollars losses to utilities and banks in past. Although, cyber security laws and systems have been developed yet the risk is too great to ignore. 
Overall thrust of the internet services providers is high throughput whilst utility protection and control equipment focus is real-time secure and fast services. Performance metric for internet is throughput but power systems are sensitive to delays. Power system communications are periodic for monitoring and rare but urgent during faults. The smart grid communication data would require delay requirements from a few ms to several minutes. Internet delay sensitivity threshold is $100 \mathrm{~ms}$ whilst power system delay sensitivity is as low as $3 \mathrm{~ms}$. Internet supports peer-to-peer communications but power system under topdown (centre to device) and bottom-up (device to centre) restricts it in local area networks due to security concerns. Internet is built upon IP protocol (may move to IPv6) but power system may use heterogeneous protocol stacks. Electric grid SCADA systems used earlier DNP3 [19] communication protocol consisting of physical, data link, transport, and application layers, which recently has been ported over TCP/IP layer rendering it a three layer protocol. Substation automation systems use IEC 61850 standard for Ethernet based communications. IEC 61850 specifies a series of protocols for various time critical services including TCP/IP, UDP/IP and MAC stack for time critical trip/close commands. Power system messages can not afford to stand in long queues waiting their turn to go. IEC 61850 standard [20] has fixed delays of 3 and $10 \mathrm{~ms}$ for $1 \mathrm{~A} / \mathrm{P} 1$ and $1 \mathrm{~A} / \mathrm{P} 2$ type messages during faults; 20 and $100 \mathrm{~ms}$ delays for $1 \mathrm{~B} / \mathrm{P} 2$ and $1 \mathrm{~B} / \mathrm{P} 1$ for routine data communication among automated systems; and 100 to 500ms delays for readings monitoring applications.

Power delivery and management in smart grid context require secure communications which is likely to become vulnerable to hackers and opportunists through physical layer spread all over the country and even beyond through internet. Data availability, confidentiality and integrity are the prime concerns of smart grid system operation. Delay in time bared data is regarded as failure to supply data to run the system. Communication system must be able to self-guard against information modification attacks from remote phase measuring units, instrument transformers, telemeters and data processing centres otherwise the integrity of the whole system stands compromised. Previous history of electric utilities, banks and governments shows the hackers/intruders somehow managed to break passwords and electronic barriers causing huge losses. Now the online systems are more secure due to multiple time consuming key management techniques yet power system communications are delay sensitive. If any hacker simply manages to cause delay in trip and control messages he succeeds to bring down power system that in the case of widespread interference may cause blackout. Intelligent meters are vulnerable to manipulations to hardware manipulations (shielding the antenna of a wireless module such as WiFi 802.11 or ZigBee 802.15.4) and firmware (heart beat signals of smart meter's flash memory are possible by skilled attackers). Utility infrastructure is vulnerable to HAN sniffing, meter emulation, meters take over and access to data concentrator even centres. Web based threats have no limit and may take the form of smart meters, encryption codes, data and relay settings [16].

Critical trip and control data consists of small quantity but it needs dedicated channels in anticipation to congestion on ordinary data monitoring links. When critical data moves through a common or dedicated link cyber security measures may require time consuming authentication inquisition which can delay trip/control messages. We can not use long complex algorithms to investigate message modifications, through interlocked security checks in view of emergency situation on power system during real or fake fault message. Computerized networks may be able to sort out modifications after complex long time processing which smart system can not tolerate. Cyber attacks may originate from anonymous sources to delay, block or corrupt critical messages. Denial of service (DoS) attack may easily be launched through physical layer. Channel jamming attacks on wired and wireless services have been reported easy options for intruders [21]. DoS attack may evolve through traffic jamming in application layer network exhausting computer resources [22], buffer flooding in transport layer [23], ARP spoofing in MAC layer to target availability as well as integrity [24], and jamming in substation physical layer [22]. False data injection may fail SCADA system to recognize DC status and power system state estimation to bring the smart grid buzz down to knees.

Advanced metering infrastructures (AMI) and home area networks (HAN) being intelligent parts can render themselves to be nests for intruders. AMI provides interaction between consumers and utilities 
regarding consumption readings, and HAN supplies interaction access between consumers and market regarding prices. If intruder manages to cross these borders, he can play with intelligent electronic devices (IED) settings which has happened in past in banks, water, gas and power utilities leading to huge losses. AMI and HAN are sensitive to a few minutes to a few hours but smart grid state estimation, control (generation), transmission and distribution (protection) systems are sensitive to $3 \mathrm{~ms}$ to $3 \mathrm{sec}$. Electric grid is designed to tolerate faults up to $3 \mathrm{sec}$, the smart grid is expected to be even more sensitive. These timing and security limitations are based on information available for zombie electric grids but what about the undercurrents of smart grids when they are conscious during normal operation and faults. DoS attacks such as DDoS attacks [25] and Morris worm attacks [26] in past deteriorated 10\% of internet throughput performance.

Communication capacity limitations, managed attacks, faults and congestions virtually render smart grid a potent risk to public and utilities. Phase measurement units (PMU) are placed over widespread geographical locations. Power system operation, control and protection depend on PMU outputs which can be hacked by intruders and during natural calamities [27]. It is claimed that the ordinary protection schemes are based on over current or inverse time characteristics which take longer time to trip wasting lot of energy during faults that sounds interesting and worth harvesting but amount of energy loss is just a few kWh. Smart algorithms are shown without transient stability studies how the current chopping phenomenon will cause surges $(V=L d i / d t)$ if breaker opening time is reduced [28]. Telecom companies use coordinated protocols such as frequency hopping spread spectrum (FHSS), direct sequence spread spectrum (DSSS) and chirp spread spectrum (CSS) as anti-jamming schemes [29]. Frequency hopping pattern, direct sequence and chirp are the secrets which are not often valid in open communication standards such as WiFi and cellular networks. Hackers can guess the secret using multi-channel spectrum analyzer or any company employ. Uncoordinated protocols appear more secure in wireless communications and local area networks as they generate random secrets but this process takes time as shown in Table 2 [15].

Table 2. Time delays elapsed in anti-jamming schemes

\begin{tabular}{|c|c|c|c|}
\hline Scheme & Hardware & Bandwidth (MHz) & Delays (s) \\
\hline UFHSS & USRP & 1 & $1-2$ \\
UDSSS & USRP & 1 & $10-32$ \\
UFH-UDSS & USRP & 1 & $1-1000$ \\
DEEJAM & MICAz & 0.25 & $0.434-1,002$ \\
TC & MICA2 & 0.012 & $117.4-186.6$ \\
\hline
\end{tabular}

Above anti-jamming schemes take minimum 1-2 and maximum 117-186 seconds but the power system control and protection demand put a hard limit of 3 to $10 \mathrm{~ms}$ which is obviously not possible under existing schemes. Communal interference and smart grid's own computations based thinking capability are likely to be the cause of delay in response during faults. Smart grid faces real communication bottleneck during protection and control messaging. Normal AMI readings, IED status, SCADA and PMU measurements have no bandwidth or timing problem. Longer delays in data communications may delay real-time state estimation. Commercial mobile networks often take seconds but sometimes minutes to hours to reach from sender to receiver. IEDs in substations need 900 to 4800 $\mathrm{Hz}$, PMUs need 12-60 Hz, SCADA state estimation needs 0.25 to $0.5 \mathrm{~Hz}$, AMI meters and real time price demand require less than $1 \mathrm{~Hz}$ bandwidths. In case of industrial power systems the time elapsed in an event action including input I/O module processing, propagation and remote I/O modules processing times is minimally $62 \mathrm{~ms}$. If we add on overheads communication delays for security reasons then the total time exceeds the protection and control time limits [30]. Analysts argue the overall effects of smartness are hard to believe to increase stability [31]. Blackouts are on constant rise obeying power laws, which physicists regard a phase transition, a specific characteristic of complex systems [32]. 
It is advisable to define smartness of grid without taking into account dedicated protection and control lines for differential line, distance and islanding protection schemes. Design of suitable encryption schemes (AES, DES, RSA) are essential to protect data in smart grid [33]. LARCH based DES-CBC and RSA encryption suits use 16 to 1024 and 512 to 4096 bytes (key length) causing 8.79 to 8.07 and 0.83 to $32.82 \mathrm{~ms}$ delays which are to some extent tolerable by control signals. TS7250 based DES-CBC and RSA encryption schemes relatively 192.91 to 183.81 and 39.57 to $10080 \mathrm{~ms}$. Encryption and authentication are assumed necessary for smart grid. Key management is another critical issue that can allow access to hackers and intruders. Several key management systems such as SK, SKE, SKMA, ASKMA, ASKMA+ and SMOCK have been developed for power system applications [34]. Except SK (meter networks) and SMOCK (experiments) all the rest of keys are used for power system SCADA applications. Key management system can not be used on protective relay signalling therefore protection and control schemes remain vulnerable to hackers and intruders. Perhaps addition of encryption and authentication layer between application and TCP/IP layers in DNP3 and IEC 62351 may improve security against cyber attacks [35].

Smart grid conceivers claim an in-built concept of self-healing, a typical characteristic of living cells. IT experts believe the widespread deployment of power electronic devices enable self-healing feature using fast speed electronic circuit breakers and flexible AC transmission system (FACTs) technologies. Electronic circuit breakers are available up to $50 \mathrm{kV}$ levels even if available they cause high voltages due to current chopping $(V=L d i / d t)$ phenomenon. Smart grid is also expected to supply higher power quality electricity. Smart grid conceivers claim use of intelligent relays and autoreclosures to realize self healing [36]. Electrical engineers know the major power quality concern is the voltage sag which arises during short circuit fault. If autoreclosing relay continues trying on three phase bolted short circuit the result would be recurring voltage sags dipping voltage on distribution circuits to multiply evil rather than correcting so called self-healing. A recent study has shown the voltage dips and interruptions cause \$104 billion to $\$ 164$ billion economic losses to customers alone [37]. As a matter of fact customers had best quality power in past before widespread use of nonlinear electronic devices. Quality of power can not improve by definition with use of electronic devices as they themselves are the cause of problem. Smart grid super structure stands on communication technologies whose components are made of electronic devices. Idea of improving system scale power quality using power devices reflects me an attempt to treat the good with cells of evil. Addition of power electronics mimics like adding citric acid to milk for curing. The integration of power electronics and ICT into system will cause new problems like harmonics instead of supply any better quality power. It is an established reality that the causes of voltage sags and swells are short circuit faults on power systems but causes of harmonics, resonant over voltages, transients, spikes and notches are the electronic devices. Nobody can expect smart grid to supply better power quality whatsoever.

\section{Economic Challenges}

The grand transition from electric to smart grid consists of vision, roadmap, rollout, implementation, and the perceived outcome. Academic talks look promising but problems starts when it comes to pay, especially for unknown outcome. Change of existing meters to advance metering infrastructures, electromechanical devices to digital hardware, mysterious power system operation to live visualization, limited control to proactive automations, dumb metals to intelligent hardware, unidirectional to bidirectional power flows, utility to consumer oriented storages and emergency supplies for which utilities (and consumers) need to spend huge sums of money now which will be gradually recovered in decades to comes in future. If smart grid promoters overcome this barrier the road ahead will be long but not bumpy. Drivers of smart grid transition project include but not limited to energy crisis, climate change, economic meltdown, ICT industry, vendors, and business resuscitation. US business impetus is on smart meters but European utilities are focusing PLC based decentralization. Electric Power Research Institute (EPRI) estimated in 2011 that an investment of \$334-\$476 billions on smart grid in USA would lead to 
benefits of $\$ 2$ trillions over times in future. A successful completion of experimental smart grid project in Korea shows the green growth vision, climate change, global warming and energy crisis types initiatives work better.

Partial reforms in utility and public distrust were the real barriers faced in smart grid project [38]. Pakistani distribution companies (DISCO) have already replaced meters thrice in past and are now planning to replace the latest electronic models with modern smart meters. They may buy the meters without HAN chips or kill switch, which is the eventual benefit of smart meter. Critics believe the prepaid meters might be better options in the presence of direct Kunda (jumpers) culture on LV lines in Karachi, Hyderabad and KPK. Power crisis and load shedding in Pakistan provide niche opportunities to meter manufacturers to dump their out dated thingamajigs by offering kick backs to corrupt utility managers. In a smart meter introductory lecture on 21 September 2010, "Rabia Garib explained to audience the electricity company consists of generation, distribution and revenue recovery. Rabia and Waters concluded the adoption of smart meters will improve distribution and power delivery". Finally discussion diverted to choice of Sun and Orackle or Microsoft and IBM, which all have nothing to do with shortage of 8000 MW people face today. Only one thing strikes sensible the sunlight, winds, and Thar coal hold the key to real energy solutions in harmony with the third industrial revolution.

LUMS University and Siemens (Germany) held a lecture in Karachi on 21 March 2012 to explain the low hanging fruits of smart grid to power crisis hit people. This technical sermon ended on setting up a smart grid lab at LUMS University for demonstrating the worth of AMI meters to NTDC and DISCO engineers. As adage goes the fish rots from head, the national institutions and incumbents must not do ingenious business with their own people. LUMS University is an education business enterprise, which can not be representative of the poor community. Management and business guys in collaboration with vendors can not teach power engineers how to operate their power system. No one teaches swimming art to infant fishes. In another address on 25 September 2012, Hassan Farooq, explained the smart grid phenomenon as integration of communication technologies in existing grid to enhance generation, transmission and utilization of power by bringing down kunda (direct jumper) culture. Naeem Zamindar, on 28 September, 2012, hurled his mobile miracle of Wimax technologies as the eventual solution to energy crisis. Power and gas companies replaced their manual meter reading mechanisms in last few years by digital kalamazoos which is being proposed to be replaced by the smart meters. In another Siemens seminar attended by MD PEPCO, NTDC Rasul Khan Mahsud, CEO LESCO Sharafat Ali Sial, CEO IESCO Javed Pervaiz, General Managers, Chief Engineers, officials from NTDC, and distribution companies showed interest in implementing Smart Grid solutions to bridge gap between electricity supply and demand in the country. Smart grid may have potential for saving power wasted during short circuit faults. Authors believe a short circuit fault on distribution line involving 2000A current, $3 \Omega$ fault resistance for $500 \mathrm{~ms}$ duration wastes just $1.67 \mathrm{kWh}$ energy on lines which can be saved reducing fault detection times using fast new breakers. Any attempt to reduce circuit breaker physical opening time will also cause current chopping problem. Proposals to save power by reducing trip times using power electronic circuit breakers [39] may awaken the dormant ogre of power system transient stability and power quality issues compromising the second premise of smart grid. Linking smart meters to demand response resembles converting homes into business stock markets.

Question is how meters increase electricity in the presence of kunda culture and straight-faced-refusal to pay electricity bills? smart grid, smart meters and renewable energies are three different types of projects. The smart meter notion has nothing to do with power and energy crisis except using pre-paid meters for power rationing [40]. William Tucker writes on smart grids "... The second premise is that the smart grid will help integrate wind and solar energy - the two balky "renewables" that have the disadvantage of not being dispatched, when we want them (through smart grid). With the smart grid, wind and solar generation will always be available somewhere and so can be conveyed to where it's needed. But these are different things. The true "smart grid" will be a digitalized distribution system that conveys real-time information. Incorporating remote wind and solar, on the other hand, will require an upgraded grid, something entirely different. Our present 345-kilovolt AC transmission wires can't do it without 
unacceptable line losses. We will need to rebuild to 765-kilovolt DC system - something that could take decades and easily cost several trillion dollars." According to Pike Research report the smart meter shipments in second half of 2012 grew in comparison to first half. Total volume reached over 19.75 million meters worldwide in 3rd quarter of 2012 and 20.95 million meters in 4th quarter of 2012. China remained the major importer of smart meters in last quarter of 2012. After ARRA, except few small municipal and cooperative utilities, no large scale meter deployment in Europe and USA, as announced in second half of 2012. Brazil has decided to not upgrade existing meters to smart meters whatsoever [41].

Smart grid has not only inspired power professionals but also to mechanical engineers who have started thinking in terms of thermal batteries, combine heat and power smart grids [42]. Smart adoption thesis is built on integration of solar parks and wind farms to smart grid for its bi-directional power flow capability [11] but unknowingly it has hit the energy innovations research very hard. Smart grid has inflicted a never healing wound on clean technology industries which are likely to worsen the power crisis more than smart grid can help. We started graduate program in power and energy to focus renewable energy science and technologies, but emergence of smart grid has attracted all the graduate engineers toward computer and telecom based theoretical simulation studies. Department Management held a meeting on how to motivate students to take up power and energy projects and apply telecom skills for data collection and analysis purposes. Over 99\% electrical engineers in Pakistan (like many countries) are simple computer and telecom experts. It is a paradigm shift to motivate student towards power and energy in presence of ICT bliss all around. Frankly speaking, we are doing smart grid projects for live load shedding (power rationing) but its evolution is attracting students again towards telecom studies as IT did in 1990s on evolution of internet technologies. There are several independent analysts who hold the smart grid is even smarter than it appears as it is a business oriented strategy that will eventually lead to more expensive power by asking consumers to pay to cope with cyber security threats [39] in order to equip the silent sentinels and middleware protecting consumers from ambushed hackers lurking to know how Mac uses electricity on laundry, space heating and cooling applications.

\section{Social Challenges}

Smart grid vision started long ago, though the concept is very popular yet the smart grid is still regarded as a buzzword not reality [43]. Meter data collection, storage, and processing techniques do not seem to be secure. Absence of live real-time data collection and analysis tools further complicate the SCADA system. Cyber attacks render WAN protection and control vulnerable. We are talking of un-dead zombie system, which when alive will wave its own demands yet unknown to conceivers. Smart grid forensic challenges may include minimum privacy and adequate security [44] due to long inquisition based authentication and encryption procedures varying under different types of key management schemes. Even in the best case, it will expose public health, mental conditions, economic, personal like dislike secrets to at least the utility staff which can fall prey to criminal blackmailers. In terrorism hit countries like Pakistan, bank officials have been tracked down to be responsible for pointing out rich people to robbers, dacoits, looters, kidnappers and abductors. Utility operators are not different from bank operators so the public privacy and security can be compromised through simple consumption and billing data. Pakistan has computerized national registration system which tracked down false voters but minister for internal affairs mistakenly threatened public to block their identity cards on non payment of electricity bills. This threat will be accounted by courts on deployment of AMI in future for fear of AMI and national registration linkage. It may be useful for developed countries but not for developing nations which are the primary market for dumping ICT hardware under name of smart grid. Current energy management systems considered for smart grid application are limited to manual remote controlled, insecure and thick simple monitoring or maximum web and phone based techniques [45]. Smart grid operators might be expecting money from consumers to improve their infrastructures in the name of societal revolution charges like utility fuel adjustment and overhead charges practices.

Smart grid business managers may use print, electronic and social media to change the public mind set. Media scoundrels and presstitutes have no morality in presence of never satisfying money appetite. We 
have to be aware of the matrix to which our people are plugged. You might have heard buzz words like thinking wires, digital transformers, bi-directional power flows, advance metering infrastructure, selfhealing transmission networks, super smart grids, smart power pucks, societal revolution, democratization of energy, picopower plants, prosumers (pliant consumers), and superconducting fault current busters. Current 300MW heat and power capacity of prosumers is expected to rise to $9000 \mathrm{MW}$ by 2022 [41]. Mobile miracles come to save humanity from oil addiction and planet from climate changes. ICT devices will be integrated into power system infrastructure to transform the dumb electric grid into intelligent listening, thinking and responding smart grid. Counting on wireless WiFi, Wimax, and blueTooth technologies General Pact Radio Service (GPRS) data transmission (three times faster than fixed telecom networks and ten times faster than switched data services) will undertake to shrink world on you palm using Global System for Mobile (GSM) networks. Global Positioning System (GPS) allows interaction between internet, mobiles and machines. GPRS uses same protocols as in internet like wireless application protocol (WAP) which is similar to internet hyper text transfer protocol (HTTP) and file transfer protocol (FTP). WAP and FTP are used to communicate between word wide web (WWW) and mobile phones through GPRS. The power crisis can not exist in presence of iPad, iPhone and other gizmos in presence of advance energy management softwares. As adage goes, he who knows, does, who does not, starts teaching management.

IT morons keep on speaking without break for hours but they will never reply how AMI, IT and ICT devices will help increase generation and protect the system during faults. Biz community relies on dumping through warranty certificates which are either lost or often futile. Even if you pursue the vender, they will eventually throw responsibility on you for mishandling delicate doohickey which needs new software that cost half of its price. If you read narrow words bellow the bottom line you will see company terms and conditions. Deployment of AMI is not state rather states sponsored business against their own and other countries poor masses. How a jobless man can afford to agree to pay $\$ 200$ for a new smart meter. Out of $\$ 1900$ trillion worth of all things over $90 \%$ resources are in possession of elites but they are crying to snatch the other $10 \%$ for over 7 billion people on earth. The smart grid notion is fine to certain extent, to deploy communication technologies to conduct live load shedding discussed above, but perception of enhanced generation is misleading as negawatts come from efficiency of machines not from increase in communication facilities. A suitable islanding scheme can immediately reconfigure power system in equal generation and load basis islands to avoid blackouts during large power swings. A recent power swing on Pakistan WAPDA grid system led to complete breakdown of national grid on 24 February, 2013. WAPDA officials told they are planning to implement electrical islanding scheme to avoid recurrence of such events. Media hype on smart grid is a white propaganda and millennial deception against people and public utilities. We had a lot of student working on renewable energy technologies worldwide, but return of telecom (Return of Ra) wearing mask of smart grid has hacked most of them to computer simulation based projects again.

Emergence of ICT as bolt from blue has killed renewable energy interest among students which was the last hope after end of oil in 2050s, natural gas in 2070, uranium in 2090s and coal in 2150s. Smart grid notion has led governments to kill clean tech industry by choking innovation funds [46]. Governments do not want technology providers but solution providers. This technology convergence started in 2012 in India where the Telecom Regulatory Authority of India (TRAI) asked to incumbents to power $50 \%$ of all rural telecom base station towers and $33 \%$ of all urban towers in the country by hybrid solutions within 5 years. Battery and fuel cell based solutions using renewable energy technologies are available in market. Off grid revenue is likely to increase from $\$ 2500$ millions in 2013 to $\$ 25,000$ in 2020 . It is time to buy gas from Iran and power from India. Southern African Power Pool (SAPP) is a consortium of 12 utilities operating across 12 neighbouring countries in Africa (Angola, Botswana, Democratic Republic of the Congo, Lesotho, Malawi, Mozambique, Namibia, South Africa, Swaziland, Tanzania, Zambia, and Zimbabwe). These 12 countries constitute a current capacity of $60 \mathrm{GW}$ and a population of 189 million people. The aim is to create a common market for electricity - with all utilities acting without taking advantage of one another. World looks at it as a new BRIC in Africa. SAPP has 
60,904 MW power for 189 million people including 53,693 MW from conventional and 7,211MW from renewable energy sources against which Pakistan has just 12,000 MW power for 200 million people. SAPP is a good example for regional utilities corporations to solve their energy problems. Pakistan, India, Sri Lanka, Nepal and Bangladesh have huge common hydroelectricity potential which is being lost due to their trivial conflicts.

Geo energy politics also plays vital role in deepening energy and power crisis. India and Pakistan were on verge of signing Iran-Pakistan-India (IPI) gas pipeline project but USA offered Indians nuclear reactors which failed the project. Pakistan kept on lurking for few years then decided to sign alone but USA is still trying to stop it. Americans want Pakistan and India to choose Uzbekistan-AfghanistanPakistan-India gas pipeline and power projects which are not possible due to ongoing war in Afghanistan. Pakistan tried to get power from Tajikistan but India asked lower riparian countries to oppose Tajik dam project on similar grounds as Pakistan opted as lower riparian against Indian Krishan Ganga dam. We have opportunities to set up regional cooperative utility corporations with SARC countries in east and ECO member states in west. Pakistan recognizes American concerns on Pak-Iran Gas Pipeline project but incumbents have no option in presence of 18 to 20 hours daily load shedding. Utilities can not ask public to pay to replace their energy meters until power crisis declines. Social environment have to be conducive enough to talk on monetary issues. If someone tries to deliver sermon to a drowning man, he would catch him to take along in deep sea. People without gas and power in chilly winter and hot humid summers would never agree to replace their meters until load shedding is controlled to a minimum acceptable level. In a local survey on option of AMI meters over $90 \%$ consumers said "utility has no electricity we don't need even existing meters?" Utility morons in developing countries fall on their own feet after listening buzzwords (jargons) from zaftig smart meter motivators. Utility managers are ever ready to make changes for kick backs, but media and courts do not let them do anything as they used to do in past. People rely on their local electronic media which can gradually educate them over time. Unfortunately our electronic media also wants to listen and deliver good advice through certain ethnic groups which limits information to their own whims and whiles. Economic crisis and load shedding hit people after getting acquaintance with use of alternatives like generators, UPS and solar cells are quite aware which type of power source costs what? All local newspapers are full of analyses of options of cheap electricity. Consumers have come to know it is more economic to produce own electricity using gas generator instead of relying on utility. Widespread choice of noisy gas generators has created another environment disaster in Pakistan whose effects are far more dangerous that simple power crisis.

\section{Human Health Hazards}

There is hardly any place on earth which is free of electromagnetic radiations. Out roofs are fitted with mobile phone towers, streets entangled with WiMAX/WiFi antennas, and homes going to be furnished with radiative smart meters. Air, food and water face serious electromagnetic, radiation, chemical and pesticide threats. Mankind may easily destroy itself by its own intelligence (said, Stafford Cripps). We are consuming oil, coal and natural gases at speed of 1000 barrels/sec equivalent every moment. The world is fast becoming a massive polluted dump (said, Melville De Mellow). Indian coal fired power plants smog and haze enters into Pakistan through trade and monsoon winds. Transboundary air pollution has become a serious concern in Southeast Asia. Intellect distinguishes between the possible and the impossible; reason distinguishes between the sensible and the senseless. Even the possible can be senseless (said, Max Born). Institutions, anchors and experts are lamenting on looming energy crisis for deregulation, decentralization and privatization. Pakistan railway reflects a stone age ruined empire. Business today consists in persuading crowds (said Stanley Lee) to get power, accumulate wealth and enjoy facilities. Where are 14th century enlightenment, frugality and hard work norms? Lottery, auction and speculations have changed the definition of high morality. It is normal business strategy to deceive public to earn money. Business has two functions: marketing and innovation. It has become fashion to rehearse ideas, innovations and creativity to promote business from the manufacturing industries to education institutions. The nature of business is always swindling. As long as revolving door policy stays enforced, there is little 
hope of attention to consumer concern. After saturation of IT, computer and telecom business the surplus experts have joined utilities to convert the existing electric grid into smart grid by integrating thinking wires in dumb grids.

The smart grid business starts with installation of AMI meters [47]. Apart from economic impacts consumers appear more afraid from electromagnetic affects. We see a multitude of wireless technologies deployed in homes, schools and workplaces. Consumers perceive extensive deployment of smart meters as a potent threat, although they have no proof. Meters are equipped with electronic cellular transmitters which use powerful bursts of RF radiations to communicate with utility data concentrators. Large scale rollout of smart meters will become a source of radiations to human health. Smart meters emit RF bursts in home far more intense than a cell phone. Smart meters significantly contribute to an environment already polluted by RF radiation through the pervasive stationing of cellular telephone towers and habitual use of wireless technologies. European scientists recommended the maximum RF exposure for humans to be less than $0.1 \mu \mathrm{W} / \mathrm{cm}^{2}$ whereas the above limits are $1 \mathrm{~mW} / \mathrm{cm}^{2}$ in USA with no limits for long term exposure. Smart meters send off radio frequency signals 9,600 to 190,000 times every day.

Radiofrequency induced bio-effects are usually taken based on thermal effects. This reason is often quoted by utilities installing smart meters on residences and telecom companies locating cellular transmission towers in populated areas. There is neither any evidence of frequency dependent RF bioeffects nor any evidence of long term safety [48]. It is assumed, never proved, the synergic effect of biochemical pollutions, nuclear and electromagnetic radiations weaken the human health, at least to tolerance extent. Public perceptions over increased cancer rate are discussed in streets but mainstream media doest not highlight their stories due to business reasons. There must a comprehensive effort on UN level to carry out detailed study of synergic effects of electromagnetic, nuclear and biochemical pollutions on humans. I do not think there are dangerous effects as the inventors, manufacturers, sellers and users live in the same environ. Development of pollution free societies in some countries confuses but depends upon occupants who they are. If we all are in the same environment then do not worry. Our brains and hearts are certainly bio-electromagnetic organs which can be affected by outside electromagnetic pollutions. There are several sources of electromagnetic radiations the smart meter is just another new one in long list of other devices. Smart grid revolution seems to be a more economic fiddle than risk of biological effects. The World Health Organization (WHO) says "there is no risk from low level, longterm exposure to Wi-Fi networks" and the United Kingdom's Health Protection Agency reports that exposure to $\mathrm{Wi}-\mathrm{Fi}$ for a year results in the "same amount of radiation from a 20minute mobile phone call." A small percentage of Wi-Fi users have reported adverse health issues after repeat exposure and use of Wi-Fi [49].

\section{Conclusions}

Protection and control timing studies by computer, and telecom engineers hardly deal with real-time power system demands. Smart grid idea is worth pursuing on certain aspects like live load shedding through AMI but enforcement of whole package in one go is likely to worsen the problem from minor shortages, peak shavings, revolving load shedding and momentary disruptions to long hauled sustained blackouts as smart grid can not respond as fast as the existing electric grid does. Complete deployment of current smart grid vision might transform the twilight into complete dark. Demand response idea is based on infinite resources which in fact are not in nature. Power professionals can not afford the enforcement of smart grid sinister from fear of complete breakdown. Smart grid vision may be a good step if it is adopted to increase negawatts (10 to 20\%) by improving energy efficiency, choosing renewable and alternative resources to cope with power and energy crisis in context of climate change. Information and communication technologies have practically diverted attention of electrical engineering students from solar and wind projects towards computer based smart grid simulation scepticism. Scope of negawatts is reasonable but that can be harvested through efficient machine designs and faster transport facilities. Smart grid vision has some realizable potentials but price of these benefits seems more than value of the eventual good. Smart grid appears to me a new form of IT revolution that made the power discipline 
crippled rather un-dead in 1990s. If we count on economic and commercial aspects the smart meter inventors seem much smarter that the ultimately perceived smart grid.

\section{References}

[1] Heydt G, Liu C, Phadke A, Vittal B. Solution for the crisis in electric power supply. IEEE Computer Applications in Power, $2001 ; 14(3): 22-30$.

[2] Wu F, Moslehi K, and Bose A. Power system control centers: Past, present, and future. Proc. of IEEE, 2005; 93(11):18901908.

[3] Nico S, Kemal A, Suleyman U. A survey of routing protocols for smart grid communications. Computer Networks, 2012; 56(11): 2742-2771.

[4] Acharjee P. Strategy and implementation of smart grids in India, Energy Strategy Reviews. DOI: 10.1016/j.esr. 2012.05.003.

[5] Dostert K. Power Line Communications. Upper Saddle River, NJ: Prentice Hall, 2001.

[6] Ferreira H, Lampe L, Newbury J, Swart T. Power Line Communications. 1st ed. New York: Wiley, 2010.

[7] Kikkert CJ. MV to LV transformer PLC bypass coupling networks for a low cost smart grid rollout. In: Proc. of 2011 IEEE/PES Innovative Smart Grid Technologies Asia (ISGT), 2011:1-6.

[8] Razazian XMU, Kamalizad A, Loginov V, Navid M. G3-PLC specifications for power line communications: Overview, system simulation and field trial results. In: Proc. of IEEE International Symposium on Power Line Communications and Its Applications, Rio de Janerio, 2010: 313-318.

[9] Lin YJ, Haniph A, Lee MY, Srinivas K. A power line communication network infrastructure for the smart home. IEEE Wireless Communications, 2012; 9(6):104-111.

[10] Koji Y, Yoshihiro K, Toshio I. A grid-responsive under frequency load-reduction control scheme. International Journal of Smart Grid and Clean Energy, 2013; 2(1):100-106.

[11] Batista NC, Melicio R, Mtias JCO, Catalao JPC. Photovoltaic and wind energy systems monitoring and building/home energy management using ZigBee devices within a smart grid. Energy, 2013; 49(1):306-315.

[12] Tomsovic K, Bakken D, Venkatasubramanian V, Bose A. Designing the next generation of real time control, communication, and computations for large power systems. Proc. of IEEE, 2005; 93(5):965-979.

[13] Galli S, Scaglione Anna, Wang Z. For the grid and through the grid: the role of power line communications in the smart grid. Proceedings of the IEEE, 2011; 99(6):998-1027.

[14] http://en.wikipedia.org/wiki/Super_grid

[15] Wang $\mathrm{W}, \mathrm{Li} \mathrm{Z}$. Cyber security in the smart grid: survey and challenges. Computer Networks, doi: org/10.1016/j.comnet.2012.12.017.

[16] NIST framework and roadmap for smart grid interoperability standards, Release 1.0, NIST Special publication, 2010; 1108: 877-897.

[17] Fadi A, Al-Alia AR, Al-Dalkya R, Al-Mardinia M, El-Hajjb W. Smart grid security: threats, vulnerabilities and solutions. International Journal of Smart Grid and Clean Energy, 2012; 1(1):1-6.

[18] Al-Omar B, Al-Ali AR, Ahmed R, et al. Role of information and communication technologies in the smart grid. Journal of Emerging Trends in Computing and Information Sciences, 2012; 3(5):707-716.

[19] Curtis K. A DNP3 protocol primer, DNP3 users group, pp. 1-8, (http://www.dnp.org)

[20] IEC 61850 standard for communication networks and systems in substations.

[21] Strasser M, Capkun S, Popper C, Cagalj M. Jamming resistant key establishment using uncoordinated frequency hopping. In: Proc. of IEEE Symposium on Security and Privacy, 2008: 64-78.

[22] Lu Z, Lu X, Wang W, Wang C. Review and evaluation of security threats on the communication networks in the smart grid. Presented at: Military Communications Conference (MILCOM'10), 2010.

[23] Jin D, Nicol DM, Yan G. An event buffer flooding attack in DNP3 controlled SCADA systems. Presented at: the 2011 Winter Simulation Conference, 2011.

[24] Premaratne U, Samarabandu J, Sidhu T, Beresh R, Tan JC. An intrusion detection system for IEC61850 automated substations. IEEE Transactions on Power Delivery, 2010; 25(4):2376-2383.

[25] Markoff J. (August 13, 2008). Before the gunfire, cyber attacks. The New York Times. [Online]. Available: http://www.nytimes.com/2008/08/13/technology/13cyber.ht\%ml?em

[26] The Submarine. [Online]. Available: http://www.paulgraham.com/submarine.html\#f4n

[27] Liu H, Bi T, Yang Q. The evaluation of phasor measurement units and their dynamic behavior analysis. IEEE Transactions on Instrumentation and Measurement, DOI: 10.1109/TIM.2013.2242611.

[28] Xyengi I, Popov M. An intelligent algorithm for the protection of smart power system. IEEE Transactions on Smart Grid, DOI: 10.1109/TSG.2013.2244621.,2013.

[29] Goldsmith A. Wireless Communications. Cambridge University Press, 2005. 
[30] Allen W, Lee T. Flexible high speed load shedding using a cross switch. 2006 Power Systems Conference: Advanced Metering, Protection, Control, Communication, and Distributed Resources, 2006: 501-509.

[31] Galli G. Where is the smartness. Presented at: the Workshop on the Evolution of the Electricity Grid: Cognitive Energy Systems, Hamilton, Canada, Mar. 19, 2010.

[32] Callaway E, Gorday P, Hester L et al. Home networking with IEEE 802.15.4: A developing standard for low-rate wireless personal area networks. IEEE Communications Magazine, 2002, 40(8):70-77.

[33] Mihaljevic MJ, Kohno R. On wireless communications privacy and security evaluation of encryption techniques, in: Proc. of IEEE Wireless Communications and Networking Conference (WCNC '02), 2002.

[34] Zhang J, Kasera SK, Patwari N. Mobility assisted secret key generation using wireless link signatures. Presented at: IEEE Conference on Computer Communications (INFOCOM'10), 2010.

[35] Li F, Luo B, Liu P. Secure information aggregation for smart grids using homomorphic encryption. Presented at: IEEE Conference on Smart Grid Communications, 2010.

[36] Joseph P. Energy department's investment grant program advances rapidly, as scheduled. IEEE Smart Grid Newsletter, February 2013.

[37] Dirk VH, Marcel D, Johan D, Ronnie B. Choosing the correct mitigation method against voltage dips and interruptions: A customer based approach. IEEE Trans. Power Delivery, 2007; 22(1):331-339.

[38] Daphne NYM, Johannes MVDV, Jasper CI, Peter RH. Governing the transition of socio-technical systems: A case study of the development of smart grids in Korea. Energy Policy, June 2012; 45:133-141.

[39] Liang Z, Joel JPC. Service oriented middleware for smart grid; Principle, infrastructure and applications. IEEE Communications Magazine, 2013; 51(1):84-89.

[40] William T. [Online]. Available: www.infrastructist.com/2009/smart-grid-a-little-stupid

[41] Pike Research Report 920130 Smart Grid Deployment Tracker 1Q 2013.

[42] Rivarolo M, Greco A, Messardo AF. Thermo-economic optimization of the impact of renewable generators on poly-generation smart grids including hot thermal storage. Energy Convertion and Management, Jan. 2013; 65:75-83.

[43] Wolsink M. The research agenda on social acceptance of distributed generation in smart grids: Renewable as common pool resources. Renewable and Sustainable Energy Reviews, 2012; 16(1):822-835.

[44] Melike EK, Hussein TM. Smart grid forensic science: Applications, challenges and open issues. IEEE Communication Magazine, 2013; 51(1):68-74.

[45] Saima A, Yogesh S, Viktor KP. Energy management systems; State of the art and emerging trends. IEEE communications Magazine, 2013; 51(1):114-119.

[46] Adamson KA. Whitepaper. Smart Energy: Five Metatrends to Watch in 2013 and Beyond. Pike Research, 2013.

[47] The White House Blog. (October 27, 2009). President Obama Announces \$3.4 Billion Investment to Spur Transition to Smart Energy Grid. [Online]. Available: http://www.whitehouse.gov/the-press-office/president-obama-announces-34-billioninvestment-spur-transition-smart-energy-grid

[48] Polk C, Postow E. Handbook of Biological Effects of Electromagnetic Fields, Boca Raton: CRC Press, 1986.

[49] Papageorgiou CC, Hountala CD, Maganioti AE, et al. Effects of Wi-Fi signals on the p300 component of event-related potentials during an auditory hayling task. Journal of Integrative Neuroscience, 2011; 10(2):189-202. 